I would also like to raise a point about the leading article "Ups and Downs in the Health Service" (10 April, p. 62) in which it was stated that 20 psychiatric hospitals each containing more than 2,000 beds were closed down between 1959 and 1969. This would mean a reduction of 40,000 beds, but if the total number of hospital beds has only fallen from 548,676 to 528,917 and only 2,000 of those lost were non-psychiatric, this figure cannot be right. Surely what has happened is that those 20 hospitals have succeeded in reducing their number below 2,000 but have not closed down.-I am, etc.,

Ewhurst, Surrey

DAvid TIDMARSH

1 Lancet, 1971, 1, 438.

\section{Laryngeal Tuberculosis}

SIR,-In 1966 Bull $^{1}$ reported ten cases of laryngeal tuberculosis, pointing out that the appearances of the condition nowadays differed from classical descriptions where the lesions were described as ulcerative, multiple, placed mainly posteriorly and associated with advanced pulmonary lesions. In seven of the cases in Bull's series the appearances were those of carcinoma. Since that date there have been no further reports of laryngeal tuberculosis in the English literature.

We should like to record our recent experiences with this condition.

Case 1.-Male, aged 52, presented on 3 July 1969 with a six-week history of hoarseness. He smoked 40 cigarettes a day and gave no past history of tuberculosis. Mirror laryngoscopy showed a granular mass on the left cord involving the vocal process but not the commisure. A clinical diagnosis of carcinoma was made. The next day the exact extent of the tumour was assessed at direct laryngoscopy and two biopsies were take... These were reported as tuberculosis. No radiological evidence of tuberculosis was seen on the chest $x$-ray. The patient died of a myocardial infarction prior to treatment

Case 2.-Female, aged 59, with a past history of tuberculous cervical adenopathy, presented on 5 August 1969 with a fourweek history of hoarseness. Laryngoscopy revealed a granular lesion of the anterior commisure and oedema of the right vocal cord. On this occasion tuberculosis was suspected prior to biopsy. A preoperative chest $x$-ray also suggested this condition. The biopsy confirmed the diagnosis and after three months' treatment with streptomycin, P.A.S., and isoniazid the voice and appearance of the larynx became normal.

Case 3.-Male, aged 57, presented on 22 April 1971 with a two-year history of a sore throat, slight dysphagia, and occasional hoarseness. Laryngoscopy showed an exophytic tumour involving the epiglottis, aryepiglottic folds, and false cords; several glands were palpable on the right side of the neck. A clinical diagnosis of supraglottic carcinoma was made. The next day at direct laryngoscopy tumour extent was assessed, and several biopsies were taken with a view to performing supraglottic laryngectomy and neck dissection. A preoperative chest $x$-ray was not reported as showing tuberculosis, although retrospectively it was noted that the changes were compatible with this condition. The pathology report showed that the laryngeal lesion was tubercular and the patient started chemotherapy.
It appears, therefore, that tuberculosis must be considered wherever laryngeal cancer is suspected since these conditions may nowadays be clinically indistinguishable. Techniques of conservation surgery of the larynx are dependent for their success on accurate and detailed preoperative assessment of the exact extent of the tumour, and multiple biopsies must be taken. Use is also made of the operating microscope and the whole procedure may last 20 minutes.

This obviously presents risks to the laryngologist if tuberculosis has not been considered in the differential diagnosis. A routine chest $x$-ray is an obvious safeguard prior to laryngoscopy performed for biopsy of a suspected cancer.-We are, etc.,

\section{A. G. D. MARAN}

I. A. STEWART

Department of Otolaryngology,

Diversity of Dundee

1 Bull, T. R., British Medical fournal, 1966, 2, 991.

\section{Closed Injuries to the Duodenum}

SIR,-I was most interested to read your leading article on "Closed Injuries to the Duodenum" (29 May, p. 482). When living in Singapore my son, then aged $1 \frac{1}{2}$ years, fell down some stone steps and 12 hour later developed acute upper intestinal obstruction. Dehydrated and with a pyrexia of $106^{\circ} \mathrm{F}\left(41 \cdot 1{ }^{\circ} \mathrm{C}\right)$, he was hospitalized and after rehydration was taken to the theatre. $\mathrm{He}$ was found to have a large intramural haematoma in the second part of the duodenum splitting off the bile duct. The root of the mesentery, which was thick and flesh" with huge friable glands, was tightly obstructing the junction of the second and third parts of the duodenum below the haematoma. There was also severe pancrearitis. The surgeon was sure that the glands were lymphosarcomatous, did a gastrojejunostomy, and left a drain in situ. The child had a stormy recovery, with a wound abscess, followed by a subphrenic abscess and then haemorrhagic measles. At this point he was diagnosed as having coeliac disease and was put on a gluten-free diet. After one year he showed no signs of this disease and so was put on a normal diet again, and has since been extremely well. The histology of the glands showed gross viral hyperplasia when sent to two London hospitals.

Did the acute mesenteric adenitis and ensuing pancreatitis cause the obstruction of the duodenum, rupture one of its vessels, and therefore cause the intramural haematoma, or is this just an atypical presentation of closed injury to the duodenum?-I am, etc.

Ipswich, Suffolk

\section{T. HEWETSON}

\section{Radiological Training}

SIR,-I should like to draw attention to what I am sure is a completely inadverten omission in Professor A. G. W. Whitfield and others' article (29 May, p. 514)-namely, any reference to the university diplomas in radiology given by the Universities of Edinburgh, Liverpool, and Aberdeen

I appreciate that the authors are merely concerned with the training places in their region for the Conjoint Board examination, but perhaps some part of the lack of desire fondidates to stay in their training region is in fact due to the lack of a diploma identifiable with their place of training. Certainly in Edinburgh although we have the same problem of emigration of radiologists as Birmingham we do not have the other problems mentioned in this article.-I am, etc.,

Royal Infirmary,

ERIC SAMUEI

Edinburgh

SIR,-I would be grateful if you would allow me to correct an inaccuracy in the interesting observations on radiological training by Professor A. G. W. Whitfield and his colleagues (29 May, p. 514).

There is a very successful course in Leeds for both parts of the D.M.R.D. and not just Part I as stated.-I am, etc.,

K. C. Simpkins

Department of Diagnostic Radiology,

General Infirmary,

Leeds

\section{Schistosomiasis after Bathing}

SIR,-I think it useful to draw your readers' attention to a report by I. de Carneri and L. Bianchi which appeared in the Italian Giornale di Malattie Infettive e Parassitarie as I expect this periodical is probably not widely read in Britain. It tells of Italian tourists in the island of Djerba in Tunisia who took a three-day excursion into the Sahara and, south of Douz and Zaafrane, visited the oasis of El Mamoun. The desert heat naturally prompted them to prolonged bathing in pools and, out of 54 who did so, 12 contracted schistosomiasis.

I wish to emphasize that, in my view, Tunisia is a most attractive country to visit but the increasing number of British tourists should be warned against such a danger, one which indeed seems to manifest itself only in extremely remote regions.-I am, etc.

\section{St. Julian's}

Emanuel Agius

1 Carneri, I. de., and Bianchi, L., Giornale di

Malattie Infettive e Parasstarie, 1970, 22, 640

\section{Surgeons and Technical Skill}

SIR,-Mr. N. Capener's letter (12 June, p. 649) would appear to lament the loss to medical education of the requirement to dissect the entire human cadaver. In doing so he makes a number of currently unjustifiable assumptions. While they are not wholly unreasonable assumptions, decisions on matters of medical education must wherever possible be based upon proved or provable postulates, rather than personal reminiscence or hopeful inference.

We have no evidence that the dissection of the entire cadavar we used to insist upon had any beneficial effect on the development of technical skills and aptitudes helpful to future surgeons; and even less evidence that such dissection was of any lasting benefit to that majority of medical students who do not become surgeons. We have no evidence to suggest, as is implied in this letter, that dissection of the whole cadaver produced demonstrably greater benefits than the 